\title{
Creep Strain and Permeability Evolution in Cracked Granite Subjected to Triaxial Stress and Reactive Flow
}

\author{
Fan Zhang, ${ }^{1,2}$ Jianjian Zhao, ${ }^{1}$ Dawei Hu $\mathbb{D}^{2}{ }^{2}$ Qian Sheng, ${ }^{2}$ and Jianfu Shao ${ }^{1,3}$ \\ ${ }^{1}$ School of Civil Engineering, Architecture and Environment, Hubei University of Technology, Wuhan, China \\ ${ }^{2}$ State Key Laboratory of Geomechanics and Geotechnical Engineering, Institute of Rock and Soil Mechanics, Chinese Academy \\ of Sciences, Wuhan, China \\ ${ }^{3}$ Laboratory of Mechanics of Lille, University of Lille, Villeneuve-d'Ascq, France
}

Correspondence should be addressed to Dawei Hu; dwhu@whrsm.ac.cn

Received 25 June 2018; Accepted 20 September 2018; Published 10 December 2018

Guest Editor: Fengshou Zhang

Copyright (c) 2018 Fan Zhang et al. This is an open access article distributed under the Creative Commons Attribution License, which permits unrestricted use, distribution, and reproduction in any medium, provided the original work is properly cited.

\begin{abstract}
Fluid flow and fluid-rock interaction mainly take place in fracture network, consequently resulting in deformation and permeability variation of rock and deterioration of the wellbore performance. Mechanical-reactive flow coupling creep tests are performed on cracked granite under various confining pressures and acid and alkaline solution flows. The testing results show that the confining pressure and solution $\mathrm{pH}$ significantly influence the creep deformation, creep strain rate, and permeability. A primary creep stage and secondary creep stage are observed in all creep tests in this study; notably, the sample under a confining pressure of $10 \mathrm{MPa}$ and acid solution injection undergoes creep failure for over 2700 hours. The acid solution has a more obvious influence on the creep behavior than that of the alkaline solution. With an increase in confining pressure, the total creep strain and creep strain rate in the samples gradually decrease during the injection of either solution. The permeability of the samples injected with either solution gradually deceases during the testing process, and this deceasing rate increases with the confining pressure. The scanning electron microscopy observations on the crack surfaces after the creep tests show that the surfaces of the fractures injected with the acid solution are smooth due to the dissolution of the matrix, while those injected with the alkaline solution include voids due to the dissolution of quartz. These experimental results could improve the understanding of the long-term transport and mechanical behaviors of wellbore.
\end{abstract}

\section{Introduction}

Rock reservoir in subsurface energy resources is under triaxial stress condition, and hydraulic fracking is used to generate fluid transport path for the production of hydrocarbon and geothermal energy [1]. Recent studies suggest that some additives or supercritical $\mathrm{CO}_{2}$ could be used in enhanced geothermal systems to improve energy extraction $[1,2]$. The reactive ions in the fluid could cause fluid-rock interaction in rock materials [3-5]. In the long-term service period of wellbore, the rock formation is required to not only have enough bearing capacity in the early stage but also, and more importantly, meet the long-term deformation limitation as its performance deteriorates due to the coupling effect of triaxial stress and fluid-rock interaction. Previous studies [2, 6] indicated that the fluid-rock interactions have a strong influence on the physical and mechanical properties (e.g., elastic modulus, strength, and permeability) of the rock. Under long-term conditions, the application of stress may aggravate the influences chemical erosion [5, 7-10]. This phenomenon may cause the excessive rock deformation, result in instability of wellbore wall, and decrease the production. Therefore, it is highly needed to investigate the coupling effect of triaxial stress and fluid-rock interaction.

Some scholars carried out experimental studies on the triaxial mechanical behavior of granite after chemical erosion [11-14]. The effects of chemical solutions with different $\mathrm{pH}$ values on the strength and deformation of granite were discussed, and the corrosion mechanism of granite by chemical solution was also analyzed. Zhang et al. [15] carried out a triaxial compression test of granite treated by heating and rapid cooling. The experimental result showed that the granite 


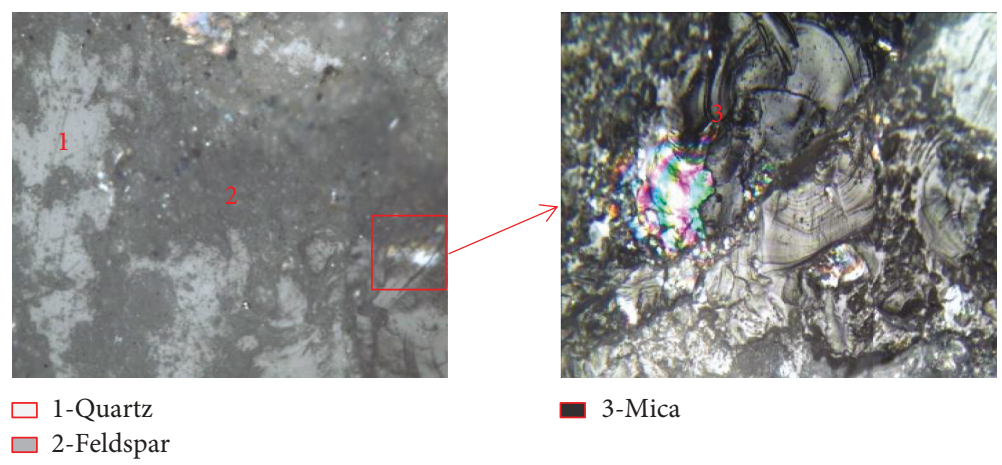

FIgURE 1: Microscopic structure of the mineral compositions.

strength tended to decrease with the increase in treatment temperature. Chen et al., Polak et al., and Wang et al. [16-18] carried out experimental studies on the effect of mechanicalhydraulic-chemical coupling on permeability and revealed the evolution of permeability with testing time. A considerable research effort has been made to investigate the effect of chemical corrosion and mechanical loading on other porous materials [11, 12, 14, 19-23] The coupling conditions, e.g., stress level, solution $\mathrm{pH}$, and rock mineral compositions, have a great impact on the mechanical and transport properties of rocks. Several constitutive models were proposed to describe the mechanical response and transport evolutions of a cementbased material subjected to mechanical-reactive flow coupling [24]. Mechanical damage induced by applied stress and chemical damage induced by chemical erosion were defined independently. The evolutions of the creep rate and chemical deterioration of materials were analyzed.

The previous investigations mainly studied porous materials, e.g., sandstone, cement, and chalk. However, the host rocks of extracting subsurface energy resources (e.g., enhanced geothermal systems, conventional and unconventional gas, and oil) have low porosities, and their permeability under intact conditions is also low. Therefore, fluid transportation and fluid-rock interaction mainly take place in cracks within the host rocks. The long-term mechanical-reactive flow coupling behavior of cracked rock is clearly different from that of porous rock and thus critical to study.

Granite materials are now widely used in many engineering applications due to their high mechanical strength and low permeability. Studying the creep properties of granite under mechanical-chemical coupling is of great significance for long-term work in many projects. In this paper, the long-term mechanical behavior of granite with preformed fractures in acid-alkaline environment is studied, and the influence of alkaline solution and acid solution on the physical and mechanical behavior of granite are analyzed. This paper is organized as follows. In Section 2, the physical parameters of granite and uniaxial/triaxial compression strength are tested. In Section 3, the creep test of granite with preformed fractures with injecting alkaline and acid solution into the samples during creep test, respectively, is presented. At the same time, the change of permeability of granite with preformed cracks in long-term creep test is monitored to prove the influence of chemical solutions.
Finally, the effects of confining pressure, the type of the solution, creep strain rate, and permeability are analyzed. The microstructure of fracture surfaces of the granite samples after creep test is also observed.

\section{Test Preparations}

The material used in this study is granite from an underground tunnel excavation, and all the samples are drilled from one large block without any observable joints. The density of the samples in their natural condition is $2.61 \mathrm{~g} / \mathrm{cm}^{3}$. X-ray diffraction tests show that the main mineral compositions are quartz (30\%), soda feldspar (21.05\%), potash feldspar (45.19\%), and mica (23.05\%). At the microscopic level, quartz grains are scattered in a matrix of soda feldspar, potash feldspar, and mica, which act to cement the larger grains (see Figure 1). The diameter and height of the samples are 37 and $74 \mathrm{~mm}$, respectively.

The intact granite samples have very low permeability, and it is difficult to achieved steady seepage in the samples. Moreover, interactions between rock and reactive solutions mainly occur in excavation damage zones, where cracks are generated in the surrounding rocks after excavation due to stress redistribution (Pepe et al., 2017). Given that tension and shear failure are the two common rock damage mechanisms observed in surrounding rocks, the samples are first subjected to triaxial compressive stress until failure, and different confining pressures, e.g., 0,5 , and $10 \mathrm{MPa}$, are applied to create different crack patterns (see Figure 2). The typical stress-strain curves of the triaxial compression tests are shown in Figure 3. The samples undergo brittle failure under the confining pressure magnitudes applied in this study. Additionally, under low confining pressure (e.g., $0 \mathrm{MPa}$ ), the sample failure is marked by a distinctive peak stress due to the coalescence of tensile cracks, ultimately splitting the sample. Under higher confining pressures (e.g., 5 and $10 \mathrm{MPa}$ ), this distinctive peak stress becomes less pronounced. The failure of the sample transitions from tensile cracking to shear cracking. A similar phenomenon has been observed in sandstone [25] and granite [8].

A thermal-hydrological-mechanical-reactive flow coupling testing system is used to perform creep tests with acid and alkaline solution injection, and the sketch diagram of this testing system is presented in Figure 4. The whole testing system is placed into a large oven to perform the tests at 


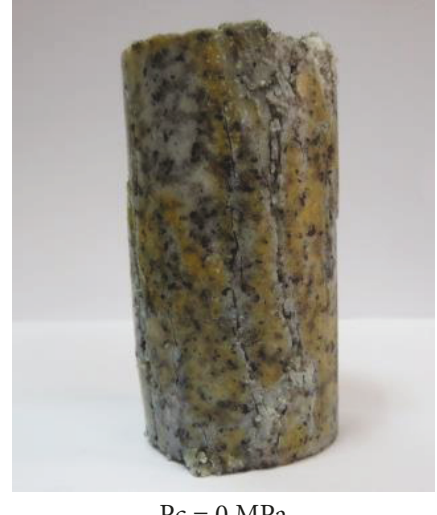

(a)

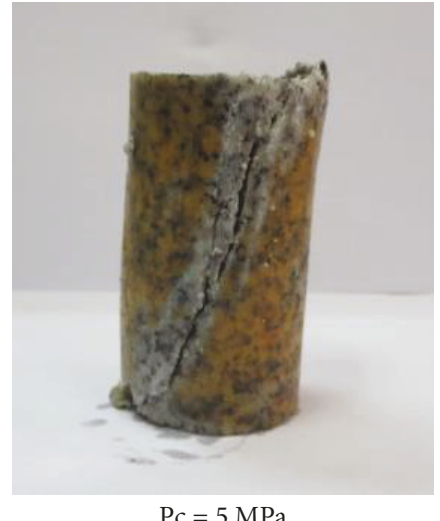

(b)

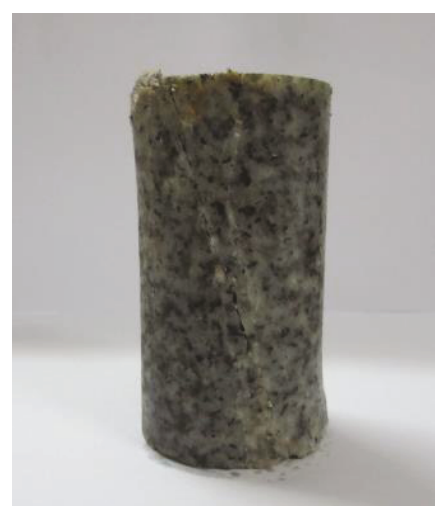

$\mathrm{Pc}=10 \mathrm{MPa}$

(c)

FIGURE 2: Crack patterns after failure.

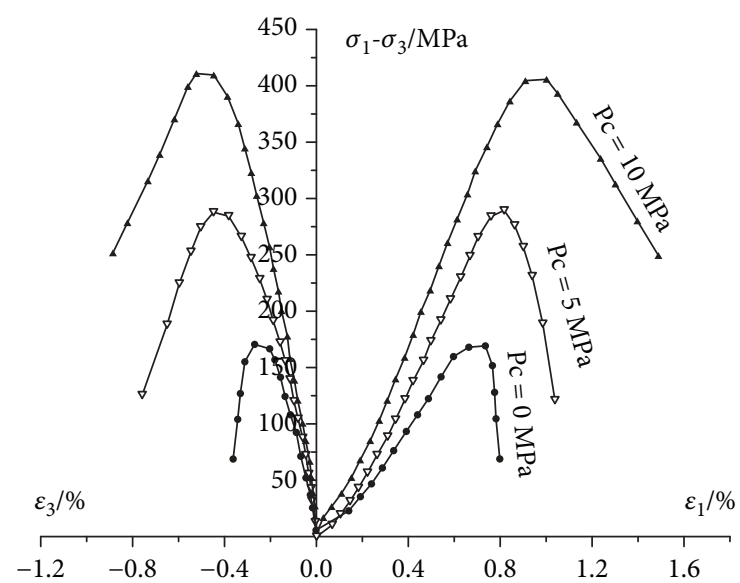

Figure 3: Typical stress-strain curves of the triaxial compression tests.

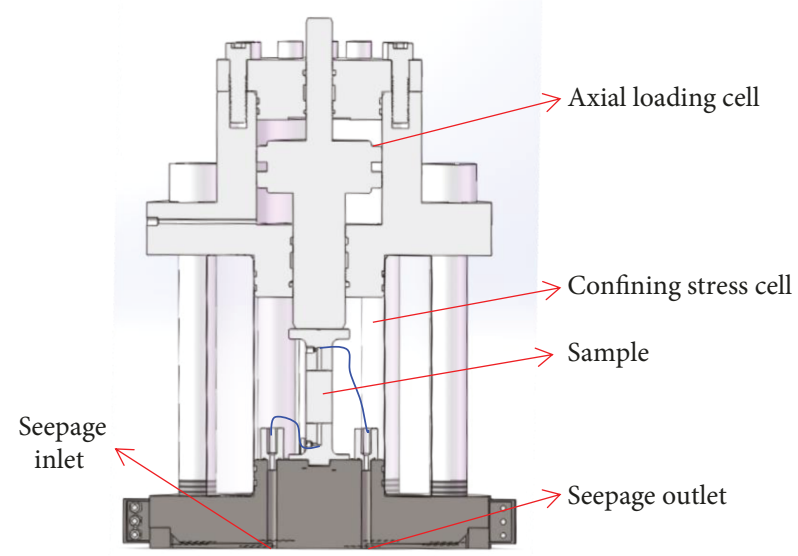

FIgURE 4: Schematic of triaxial compression apparatus.

a predetermined temperature. The testing room is also equipped with an air conditioner and is held at a constant temperature of $20 \pm 2^{\circ} \mathrm{C}$. Consequently, the temperature conditions during the tests can be controlled to a precision of $\pm 0.2^{\circ} \mathrm{C}$.
Throughout this paper, the rock mechanics sign convention is used; compressive stresses and strains are positive. Furthermore, a fixed coordinate frame is used for the cylinder sample, and the cylinder axis is parallel to the $x_{1}$ axis. $\sigma_{i}$ and $\varepsilon_{i}(i=1,2,3)$ denote the three principal stresses and strains in this frame, while $p$ is the interstitial pressure.

After the triaxial compression tests are completed, the cracked samples are directly used in the subsequent creep tests. The same magnitude of confining pressure is applied to the cracked samples after triaxial compression at confining pressures of 5 and $10 \mathrm{MPa}$, whereas a confining pressure of $2 \mathrm{MPa}$ is applied to the cracked samples after triaxial compression at a confining pressure of $0 \mathrm{MPa}$; this low confining pressure can avoid seepage flow between the sample and jacket. The axial stress is reloaded to the predetermined levels, which correspond to $70 \%$ of the residual strength of the cracked samples under confining pressures of 2, 5, and $10 \mathrm{MPa}$. Detailed information about the stress path of the studied samples is presented in Table 1.

Two kinds of solutions with different $\mathrm{pH}$ values, namely, a $\mathrm{H}_{2} \mathrm{SO}_{4}$ solution with $\mathrm{pH}=2$ and a $\mathrm{NaOH}$ solution with $\mathrm{pH}=12$, are injected into the cracked samples. The pressure at the inlet is $1 \mathrm{MPa}$, and the pressure at the outlet is identical to atmosphere pressure; a pressure gradient is thus achieved to induce seepage through the samples. A metering pump with a precision of $0.01 \mathrm{MPa}$ is used to apply the pressure gradient and record the seepage volume during the tests.

\section{Test Results}

3.1. Creep Strain Curves. Six creep tests are performed on the cracked samples; 3 levels of confining pressure and 2 solutions, with $\mathrm{pH}=2$ and $\mathrm{pH}=12$, are studied. The variations in creep strain with time are presented in Figure 5.

The creep curves of the fractured granite under mechanical-reactive flow coupling conditions show obvious creep characteristics. In the initial creep stages, the strain clearly increases with time. After a certain period, the rate of increase in the strain decreases, and the sample enters the stable stage. All the samples in this study undergo a primary creep stage and secondary creep stage, whereas sample 
TABLE 1: Detailed information of the samples used in the triaxial compression tests and creep tests.

\begin{tabular}{|c|c|c|c|c|c|}
\hline \multirow{2}{*}{ Sample no. } & \multirow{2}{*}{$\begin{array}{l}\text { Triaxial compression test } \\
\text { Confining pressure }(\mathrm{MPa})\end{array}$} & \multicolumn{4}{|c|}{ Creep test } \\
\hline & & Confining pressure $(\mathrm{MPa})$ & Deviatoric stress $(\mathrm{MPa})$ & Seepage pressure $(\mathrm{MPa})$ & Injected solution \\
\hline 1 & 0 & 2 & 34.52 & 1 & $\mathrm{pH}=2$ \\
\hline 2 & 0 & 2 & 34.52 & 1 & $\mathrm{pH}=12$ \\
\hline 3 & 5 & 5 & 48.35 & 1 & $\mathrm{pH}=2$ \\
\hline 4 & 5 & 5 & 48.35 & 1 & $\mathrm{pH}=12$ \\
\hline 5 & 10 & 10 & 63.62 & 1 & $\mathrm{pH}=2$ \\
\hline 6 & 10 & 10 & 63.62 & 1 & $\mathrm{pH}=12$ \\
\hline
\end{tabular}

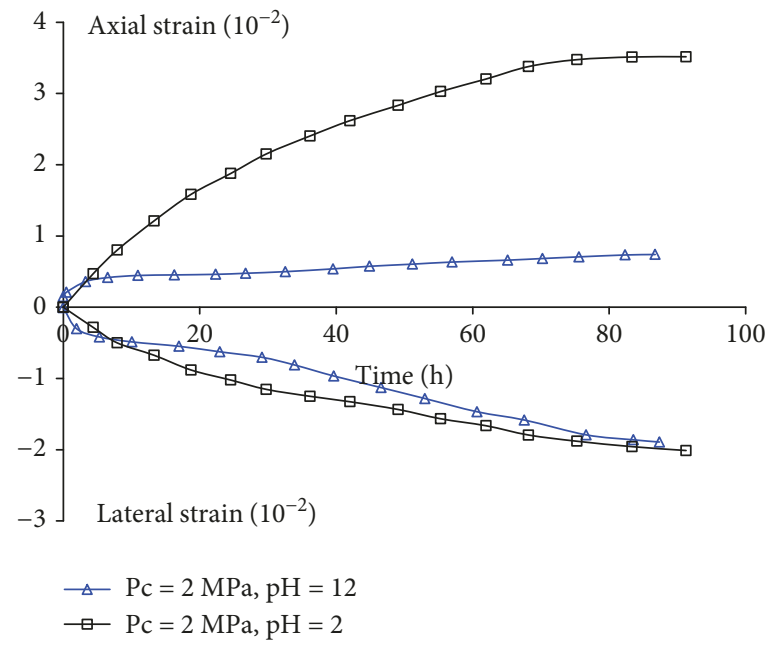

(a) $P_{\mathrm{c}}=2 \mathrm{MPa}$

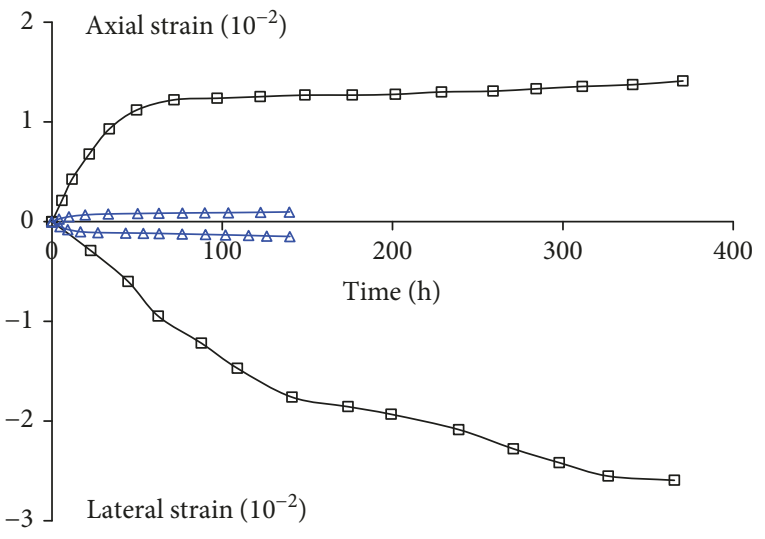

$\triangle \mathrm{Pc}=5 \mathrm{MPa}, \mathrm{pH}=2$

$\rightarrow \mathrm{Pc}=5 \mathrm{MPa}, \mathrm{pH}=12$

(b) $P_{\mathrm{c}}=5 \mathrm{MPa}$

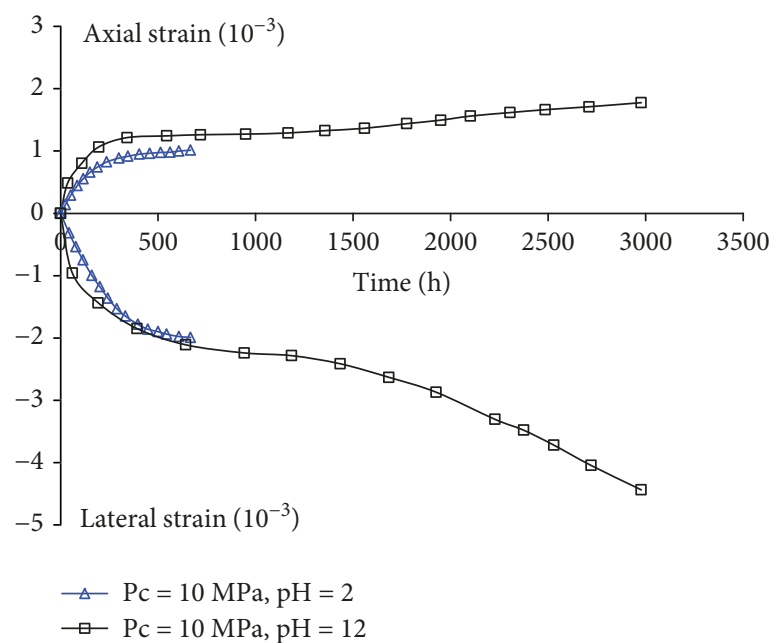

(c) $P_{c}=10 \mathrm{MPa}$

FIGURE 5: Creep strain evolutions of the cracked samples under different confining pressures and reactive solution injection.

no. 6 (confining pressure of $10 \mathrm{MPa}$ with acid solution injection, Figure 5(c)) undergoes a tertiary creep stage before ultimately losing its strength.

Compared with the alkaline solution, the acid solution induces a more obvious effect on the creep behavior. Under all confining pressures, the creep strains of the samples injected with the acid solution are greater than those injected with the alkaline solution. Moreover, the time to a stable creep strain during the injection of an acid solution is greater than that of an alkaline solution, and this phenomenon becomes more significant when the confining pressure increases. The differences in creep behavior between the samples injected with acid and alkaline solutions are attributed to the different mechanisms of the solution-mineral reactions; 


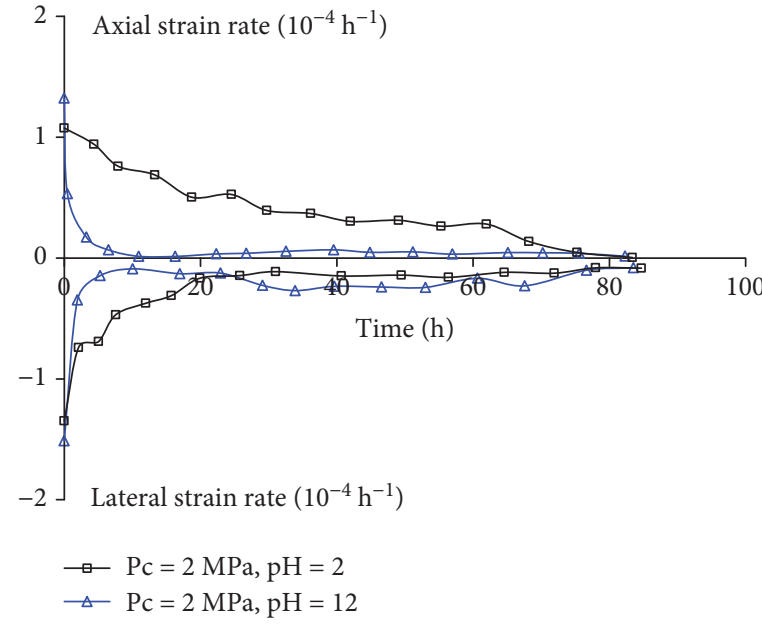

(a) $P_{\mathrm{c}}=2 \mathrm{MPa}$

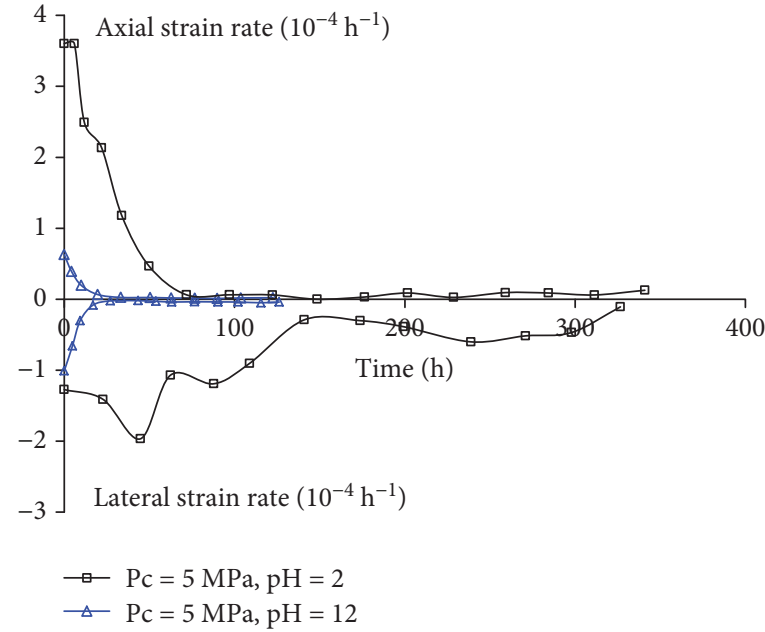

(b) $P_{\mathrm{c}}=5 \mathrm{MPa}$

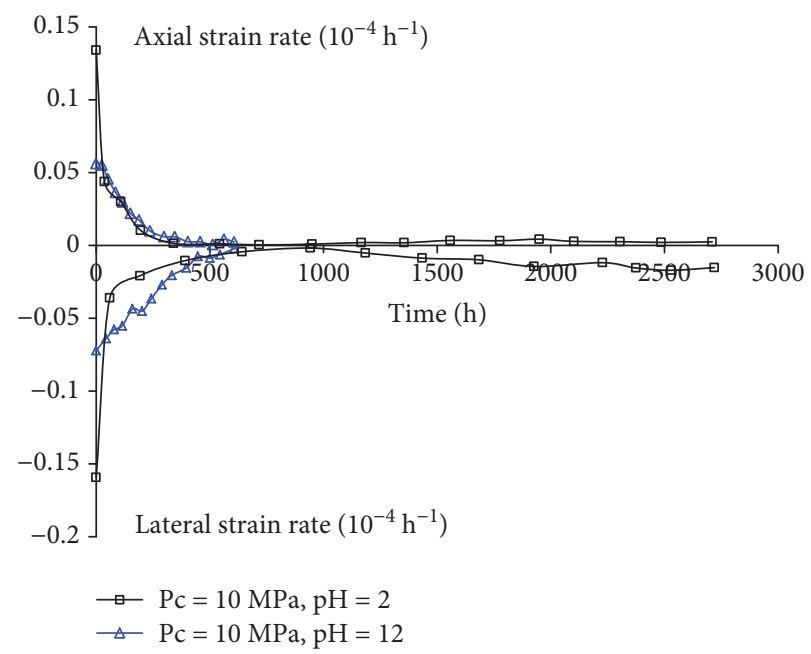

(c) $P_{\mathrm{c}}=10 \mathrm{MPa}$

FIGURE 6: Creep strain rate evolutions of the cracked samples under different confining pressures and reactive solution injection.

these mechanisms will be explained in the following sections. Similar results have been observed in artificially fractured granite $[26,27]$. The results have been shown that the feldspar and biotite are relative more sensitively reacted with the acid solution than the quartz, and the acidizing solutions change the mechanical properties of rocks. Luo et al. [26] stated that the degree of rough of crack surface decreases after $600 \mathrm{~h}$ chemical reaction, and the original rough crack surface gradually becomes smooth due to the chemical reaction of granite in chemical reagents. On the other hand, the degree of corrosion of granite under acidic conditions is higher than that under alkaline conditions; thus, the fracture surface in the acidic environment is strongly corroded, while the fracture surface in the alkaline environment is relatively rough.

The confining pressure also has a significant effect on the creep behavior. With an increase in confining pressure, the creep strains during injection of either the acid or alkaline solution gradually decrease, and the total creep strain under a confining pressure of $10 \mathrm{MPa}$ is one order of magnitude less than that under a confining pressure of 2 or $5 \mathrm{MPa}$. This phenomenon could be explained by the limitation of deformation due to confining pressure. Similar results were shown in considering the hydrologicalmechanical coupling in fractured rocks [28-30].

3.2. Creep Strain Rate. To further analyze the effect of confining pressure and solution $\mathrm{pH}$ on the creep behavior, the creep strain rates are calculated and presented in Figure 6. The creep rate is calculated from the following relation:

$$
\dot{\varepsilon}_{t}=\frac{\varepsilon_{t+1}-\varepsilon_{t}}{\Delta t}
$$

where $\dot{\varepsilon}_{t}$ represents the creep rate at creep time $t . \varepsilon_{t+1}$ and $\varepsilon_{t}$ represent the creep strains corresponding to time $t+1$ and time $t$, respectively. $\Delta t$ is the time interval between time $t$ and $t+1$.

As mentioned above, the injection of the acid solution has a more significant effect on the creep behavior than 


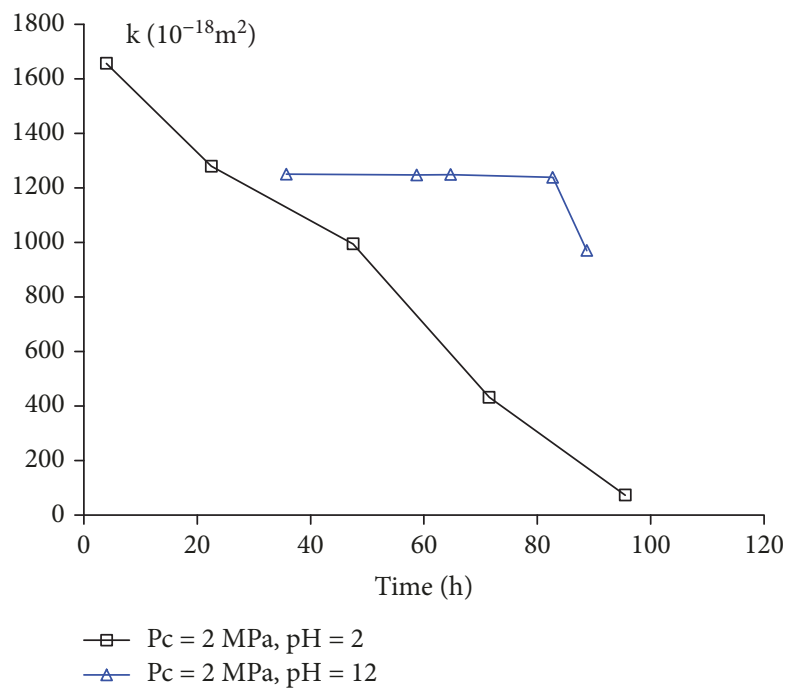

(a) $P_{\mathrm{c}}=2 \mathrm{MPa}$

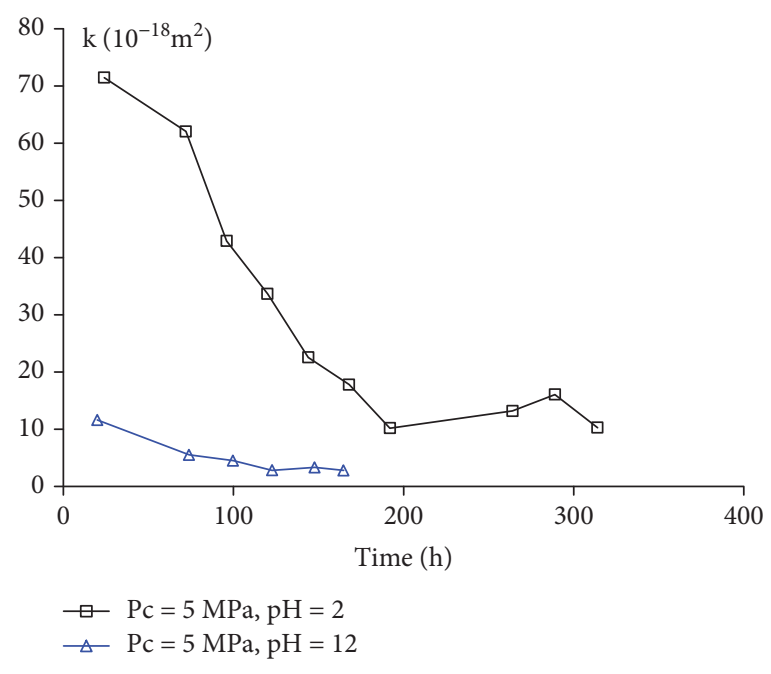

(b) $P_{\mathrm{c}}=5 \mathrm{MPa}$

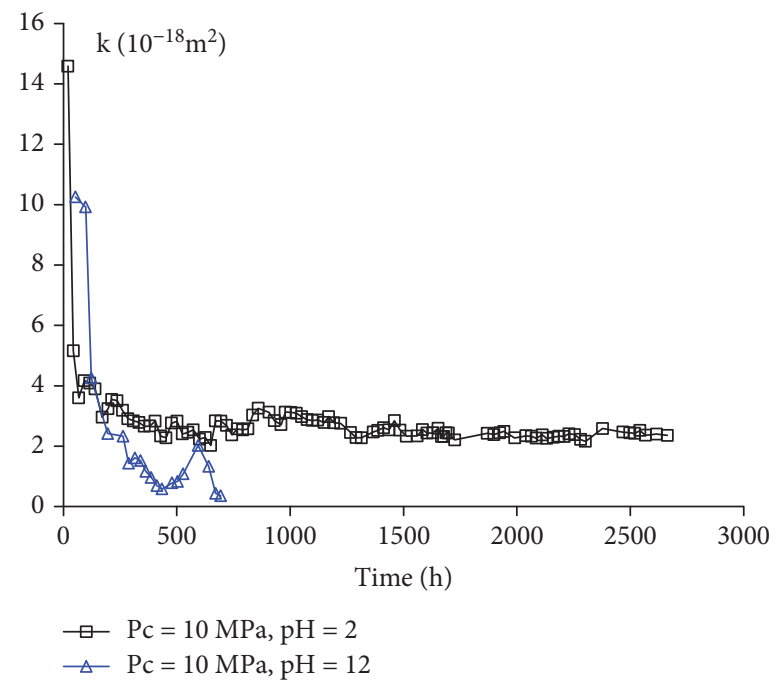

(c) $P_{\mathrm{c}}=10 \mathrm{MPa}$

Figure 7: Permeability evolutions of the cracked samples under different confining pressures and reactive solution injection.

that of the alkaline solution. The curves of creep strain rate in Figure 6 confirm these results. The creep strain rates in both the axial and lateral directions with injection of the acid solution are greater and take a longer time to reach stability than those of the alkaline solution. Notably, the creep strain rate in the lateral direction under a confining pressure of $10 \mathrm{MPa}$ and acid solution injection is significantly greater than that in the axial direction during the tertiary creep stage. Therefore, the sample undergoes volumetric dilation during the creep failure stage, and this volumetric dilation is attributed to the shear deformation of the compressive shear fractures (see Figure 2).

3.3. Permeability Tests. The permeability of the samples during the mechanical-reactive flow coupling tests is measured regularly at a predetermined time interval. Given the correlation between permeability and fracture aperture, the permeability evolutions could be used to evaluate the fracture aperture and transport properties of the cracked samples. The steady-state method is applied in this study, and the permeability of a sample can be calculated by using Darcy's law by measuring the flow rate of the seepage fluid.

$$
k\left(\mathrm{~m}^{2}\right)=\frac{Q \mu L}{\Delta p A},
$$

where $k$ is the intrinsic permeability $\left(\mathrm{m}^{2}\right)$; $Q$ is the injection flow rate $\left(\mathrm{m}^{3} \cdot \mathrm{s}^{-1}\right) ; \mu$ denotes the dynamic fluid viscosity coefficient; $L$ and $A$ are the length and cross section of the sample, respectively; and $\Delta p$ is the pressure difference between the inlet and outlet of the seepage and it is equal to $1 \mathrm{MPa}$.

In Figure 7, the initial permeability of the cracked samples during the initial creep stage is highly dependent on 
the confining pressure. The permeability under a confining pressure of $2 \mathrm{MPa}$ is two orders of magnitude greater than that under a confining pressure of $10 \mathrm{MPa}$. Consequently, the permeability of all the samples decreases as time increases and stabilizes under high confining pressures. The rate of decrease in the permeability of the samples injected with the acid solution is slightly greater than that of samples injected with the alkaline solution. Therefore, confining pressure has a greater effect on the permeability evolution than the effect of injecting a reactive solution. Similar results showed that the fracture aperture and permeability basically decrease with time under various external confinements (stresses) and solution transport for different rocks $[17,31,32]$. According to previous hydrological-mechanicalchemical coupling models $[28,30]$, the decrease in permeability is directly attributed to the aperture decrease caused by pressure solution.

\section{Discussions}

The results above indicate that the creep strain and permeability of the cracked samples depend on the confining pressure and the reactive solutions. The rock-solution reaction during the creep tests is discussed in the following subsection.

4.1. Rock-Solution Reaction. The abovementioned X-ray diffraction tests show that soda feldspar, potash feldspar, and mica account for $70 \%$ of the total mineral content of the samples, and quartz accounts for the remaining 30\%. Under the studied acidic condition $(\mathrm{pH}=2)$, the former three minerals undergo dissolution to some degree due to the acid ions [33], while quartz is nearly inactive. The reaction process can be described as follows:

$$
\begin{aligned}
& \mathrm{NaAlSi}_{3} \mathrm{O}_{8}+4 \mathrm{H}^{+}+4 \mathrm{H}_{2} \mathrm{O}=\mathrm{Al}^{3+}+3 \mathrm{H}_{4} \mathrm{SiO}_{4}+\mathrm{Na}^{+} \\
& \mathrm{KAlSi}_{3} \mathrm{O}_{8}+4 \mathrm{H}^{+}+4 \mathrm{H}_{2} \mathrm{O}=\mathrm{Al}^{3+}+3 \mathrm{H}_{4} \mathrm{SiO}_{4}+\mathrm{K}^{+} \\
& \mathrm{KAl}_{3} \mathrm{SiO}_{10}(\mathrm{OH})_{2}+10 \mathrm{H}^{+}=3 \mathrm{Al}^{3+}+3 \mathrm{SiO}_{2}+\mathrm{K}^{+}+6 \mathrm{H}_{2} \mathrm{O}
\end{aligned}
$$

However, under the studied alkaline condition $(\mathrm{pH}=12)$, the quartz undergoes slight dissolution due to the alkaline ions, while the former three minerals are nearly inactive. The reaction between the quartz and alkaline ions is described as follows:

$$
\mathrm{SiO}_{2}+2 \mathrm{NaOH}=\mathrm{Na}_{2} \mathrm{SiO}_{3}+\mathrm{H}_{2} \mathrm{O}
$$

Previous studies (Lehner, 1990; Wolery, 1992) indicated that the reaction rate in (3-5) is significantly greater than that in (6); therefore, the injection of the acid solution has a greater influence on the creep behavior than that of the alkaline solution.

4.2. Fracture Surface Observations. Scanning electron microscopy (SEM) is applied to observe the fracture surface morphology of the cracked samples after the creep tests. A sheet of $1 \mathrm{~cm}^{2}$ was taken at different positions on the fracture surface of each sample. And SEM test was performed after progress of conductive coating, and three sheets were taken for each sample. And the SEM images are shown in Figure 8. At each confining pressure, the fracture surfaces injected with acid solution are smooth, while those injected with alkaline solution are rough and include voids. According to the microscopic structure of the mineral composition, shown in Figure 1, the soda feldspar, potash feldspar, and mica grains form a rock matrix and encapsulate the quartz grains. When the acid solution comes into contact with the fracture surfaces, the rock matrix undergoes dissolution, and the dissolved ions are transported in the seepage flow. Consequently, the quartz grains debond from the fracture surface and are transported in the seepage flow once the surrounding matrix has dissolved. Therefore, the fracture surfaces in contact with the acid solution are smooth. However, when the alkaline solution comes into contact with the fracture surfaces, the quartz grains dissolve, while the surrounding matrix is nearly unaffected. Therefore, voids on the fracture surface are caused by the dissolution of quartz grains.

In addition, it can be seen from the creep curve that the sample in the acid environment under a confining pressure of $10 \mathrm{MPa}$ reaches creep failure over 2700 hours. This time is much larger than the other several conditions, for example, lower confining pressure and alkaline environment. It is apparent that the rupture surface is rough after the uniaxial/triaxial compression test. Therefore, the specimen still has the ability to withstand a certain load. Since the acidic solution is highly corrosive to the fracture surface, the fracture surface is gradually smoothed. However, the fracture surface in the alkaline solution is rough. Under the action of the creep load, the fracture surface easily leads to the piercement of the test sleeve of the wrapped sample and consequently causes the end of the test. Therefore, the creep time of the sample in an acidic environment is larger than that in an alkaline environment.

\section{Conclusions}

Triaxial creep tests were performed on cracked samples injected with reactive solutions. Three different confining pressures, namely, 2, 5, and $10 \mathrm{MPa}$, and a corresponding residual strength of $70 \%$ were applied during the tests. Additionally, two solutions with different $\mathrm{pH}$ values, namely, a $\mathrm{H}_{2} \mathrm{SO}_{4}$ solution with $\mathrm{pH}=2$ and a $\mathrm{NaOH}$ solution with $\mathrm{pH}=12$, were injected into the cracked samples during the tests. And at the same time conduct the permeability test. It can be found that the permeability of the fractured granite in the acidic solution is greater than the permeability of the fractured granite in the alkaline solution. Finally, a SEM experiment was performed on the fracture surface and can get the following conclusions:

(1) The failure mode of granite samples changes from brittle failure to ductile failure with the increase of confining pressure in the triaxial compression test. And the residual strength after the peak gradually increases with the increase of confining pressure as well 


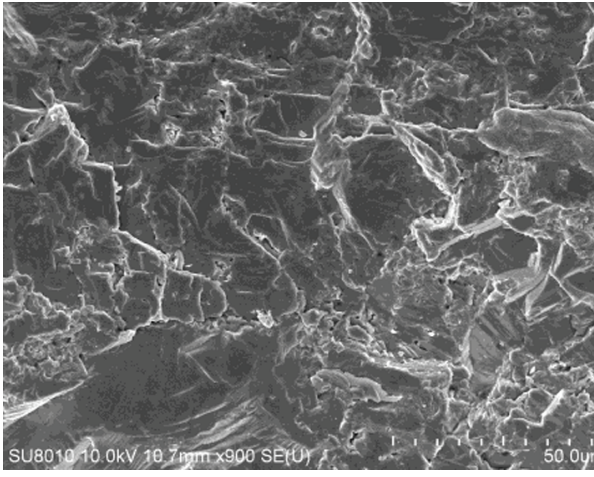

(a) $P_{\mathrm{c}}=2 \mathrm{MPa}, \mathrm{pH}=2$

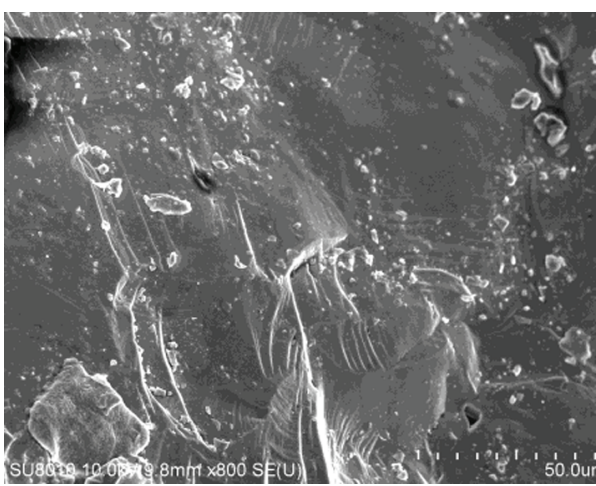

(c) $P_{\mathrm{c}}=5 \mathrm{MPa}, \mathrm{pH}=2$

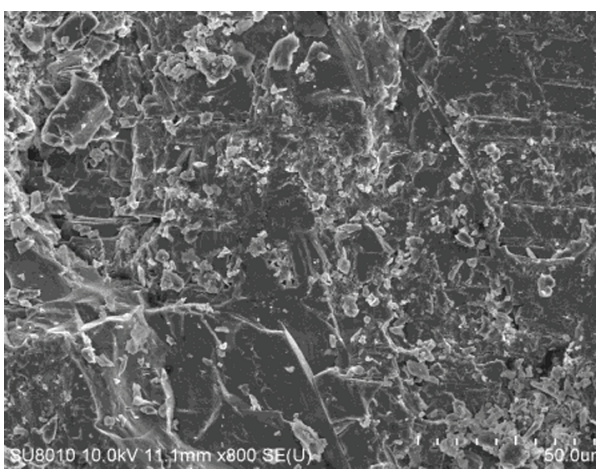

(e) $P_{\mathrm{c}}=10 \mathrm{MPa}, \mathrm{pH}=2$

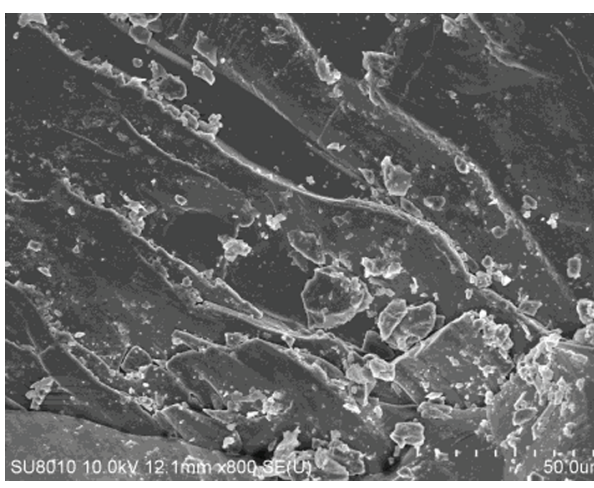

(b) $P_{\mathrm{c}}=2 \mathrm{MPa}, \mathrm{pH}=12$

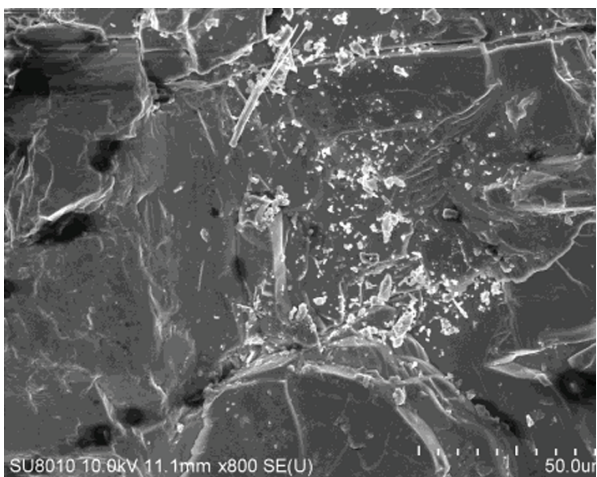

(d) $P_{\mathrm{c}}=5 \mathrm{MPa}, \mathrm{pH}=12$

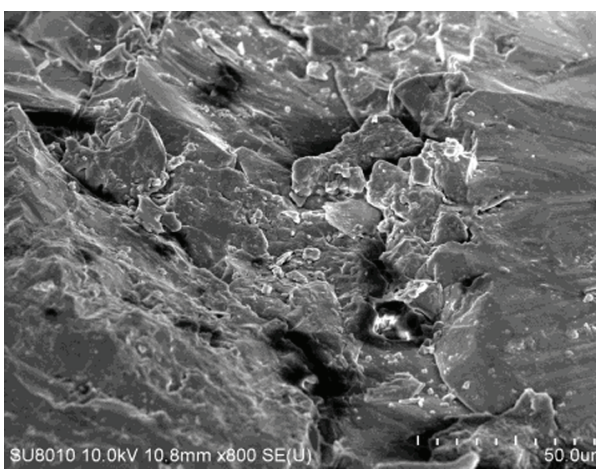

(f) $P_{\mathrm{c}}=10 \mathrm{MPa}, \mathrm{pH}=12$

Figure 8: Photographs of the microstructures at the fracture surfaces of the samples after the creep tests.

(2) The degree of corrosion of granite in alkaline environment is worse than that in acid environment

(3) Confining pressure has a significant effect on the long-term stability of granite

The study of long-term mechanical properties of granite requires more time rather than the short-term mechanical study. Therefore, the research on the creep properties of multifield coupled of granite is still rare in the world at present, especially considering the long-term performance research under the thermal-hydrological-mechanical-chemical (THMC) coupling processes. So, the next work will focus on the long-term mechanical properties of granite under multiphysics coupling conditions.

\section{Symbols}

$P_{\mathrm{c}}: \quad$ Confining pressure

$x_{1}$ : Axis direction of pressure chamber

$\sigma_{i}: \quad$ Principal stresses in this frame $(i=1,2,3)$

$\varepsilon_{i}$ : $\quad$ Principal strains in this frame $(i=1,2,3)$

$p: \quad$ Interstitial pressure

$t$ : Creep time

$\dot{\varepsilon}_{t}: \quad$ Creep rate at creep time $t$

$\varepsilon_{t}$ : Creep strains corresponding to time $t$

$\varepsilon_{t+1}$ : Creep strains corresponding to time $t+1$

$\Delta t$ : Time interval between time $t$ and $t+1$

$k$ : Intrinsic permeability

$Q$ : Injection flow rate 
$\mu$ : Dynamic fluid viscosity coefficient

$L: \quad$ Length of the samples

$A$ : $\quad$ Cross section of the samples

$\Delta p$ : Pressure difference between the inlet and outlet of the seepage channel.

\section{Data Availability}

The experimental data used to support the findings of this study are included within the article.

\section{Conflicts of Interest}

The authors declare that they have no conflicts of interest.

\section{Acknowledgments}

Financial support from the National Sciences Foundation of China (nos. 51479193 and 51779252) and the "100 Talent Program" of the Chinese Academy of Sciences is gratefully acknowledged.

\section{References}

[1] E.-S. Salama, M. B. Kurade, R. A. I. Abou-Shanab et al., "Recent progress in microalgal biomass production coupled with wastewater treatment for biofuel generation," Renewable and Sustainable Energy Reviews, vol. 79, pp. 1189-1211, 2017.

[2] Y. Pan, T. Tian, C. O. Park et al., "Survival of tissue-resident memory $\mathrm{T}$ cells requires exogenous lipid uptake and metabolism.," Nature, vol. 543, no. 7644, pp. 252-256, 2017.

[3] H. Milsch, A. Seibt, and E. Spangenberg, "Long-term petrophysical investigations on geothermal reservoir rocks at simulated in situ conditions," Transport in Porous Media, vol. 77, no. 1, pp. 59-78, 2009.

[4] J. Taron, D. Elsworth, and K.-B. Min, "Numerical simulation of thermal-hydrologic-mechanical-chemical processes in deformable, fractured porous media," International Journal of Rock Mechanics and Mining Sciences, vol. 46, no. 5, pp. 842-854, 2009.

[5] H. Zhou, D. Hu, F. Zhang, J. Shao, and X. Feng, "Laboratory investigations of the hydro-mechanical-chemical coupling behaviour of sandstone in $\mathrm{CO}_{2}$ storage in aquifers," Rock Mechanics and Rock Engineering, vol. 49, no. 2, pp. 417-426, 2016.

[6] Q. Wei, F. Xiong, S. Tan et al., "Porous one-dimensional nanomaterials: design, fabrication and applications in electrochemical energy storage," Advanced Materials, vol. 29, no. 20, article 1602300, 2017.

[7] X. Chen, S. F. Thornton, and J. Small, "Influence of hyperalkaline $\mathrm{pH}$ leachate on mineral and porosity evolution in the chemically disturbed zone developed in the near-field host rock for a nuclear waste repository," Transport in Porous Media, vol. 107, no. 2, pp. 1-17, 2015.

[8] D. Hu, H. Zhou, J. Shao, and F. Zhang, "4- Stress-induced permeability evolutions and erosion damage of porous rocks," in Porous Rock Fracture Mechanics, pp. 63-92, Woodhead Publishing, 2017.

[9] V. R. Sandeep, A. Chaudhuri, and S. Kelkar, "Permeability and flow field evolution due to dissolution of calcite in a 3-D porous rock under geothermal gradient and through-flow," Transport in Porous Media, vol. 112, no. 1, pp. 39-52, 2016.

[10] C. Zhao, B. E. Hobbs, A. Ord, P. Hornby, and S. Peng, "Effect of reactive surface areas associated with different particle shapes on chemical-dissolution front instability in fluidsaturated porous rocks," Transport in Porous Media, vol. 73, no. 1, pp. 75-94, 2008.

[11] A. Fakhimi and B. Hemami, "Rock uniaxial compression test and axial splitting," Procedia Engineering, vol. 191, Supplement C, pp. 623-630, 2017.

[12] M. G. Karfakis and M. Akram, "Effects of chemical solutions on rock fracturing," International Journal of Rock Mechanics and Mining Sciences \& Geomechanics Abstracts, vol. 30, no. 7, pp. 1253-1259, 1993.

[13] S. Miao, M. Cai, Q. Guo, P. Wang, and M. Liang, "Damage effects and mechanisms in granite treated with acidic chemical solutions," International Journal of Rock Mechanics and Mining Sciences, vol. 88, Supplement C, pp. 77-86, 2016.

[14] G. M. Ren, H. Wu, Q. Fang, J. Z. Liu, and Z. M. Gong, "Triaxial compressive behavior of UHPCC and applications in the projectile impact analyses," Construction and Building Materials, vol. 113, Supplement C, pp. 1-14, 2016.

[15] F. Zhang, J. Zhao, D. Hu, F. Skoczylas, and J. Shao, "Laboratory investigation on physical and mechanical properties of granite after heating and water-cooling treatment," Rock Mechanics and Rock Engineering, vol. 51, no. 3, pp. 677694, 2018.

[16] W. Chen, J. Liu, F. Brue et al., "Water retention and gas relative permeability of two industrial concretes," Cement and Concrete Research, vol. 42, no. 7, pp. 1001-1013, 2012.

[17] A. Polak, D. Elsworth, J. Liu, and A. S. Grader, "Spontaneous switching of permeability changes in a limestone fracture with net dissolution," Water Resources Research, vol. 40, no. 3, 2004.

[18] H. Wang, W. Xu, J. Shao, and F. Skoczylas, "The gas permeability properties of low-permeability rock in the process of triaxial compression test," Materials Letters, vol. 116, Supplement C, pp. 386-388, 2014.

[19] F. Agostini, Z. Lafhaj, F. Skoczylas, and H. Loodsveldt, "Experimental study of accelerated leaching on hollow cylinders of mortar," Cement and Concrete Research, vol. 37, no. 1, pp. 71-78, 2007.

[20] X.-T. Feng, W. Ding, and D. Zhang, "Multi-crack interaction in limestone subject to stress and flow of chemical solutions," International Journal of Rock Mechanics and Mining Sciences, vol. 46, no. 1, pp. 159-171, 2009.

[21] F. H. Heukamp, F. J. Ulm, and J. T. Germaine, "Mechanical properties of calcium-leached cement pastes: triaxial stress states and the influence of the pore pressures," Cement and Concrete Research, vol. 31, no. 5, pp. 767-774, 2001.

[22] D. Kuhl, F. Bangert, and G. Meschke, "An extension of damage theory to coupled chemo-mechanical processes," in European Congress on Computational Methods in Applied Sciences and Engineering (ECCOMAS 2000), CD-RoM, Barcelona, Spain, 2000.

[23] S. Y. Xie, J. F. Shao, and N. Burlion, "Experimental study of mechanical behaviour of cement paste under compressive stress and chemical degradation," Cement and Concrete Research, vol. 38, no. 12, pp. 1416-1423, 2008.

[24] D. Hu, H. Zhou, F. Zhang, and J. Shao, "Modeling of shortand long-term chemomechanical coupling behavior of 
cement-based materials," Journal of Engineering Mechanics, vol. 140, no. 1, pp. 206-218, 2014.

[25] D. W. Hu, H. Zhou, F. Zhang, and J. F. Shao, "Evolution of poroelastic properties and permeability in damaged sandstone," International Journal of Rock Mechanics and Mining Sciences, vol. 47, no. 6, pp. 962-973, 2010.

[26] J. Luo, Y. Zhu, Q. Guo et al., "Chemical stimulation on the hydraulic properties of artificially fractured granite for enhanced geothermal system," Energy, vol. 142, pp. 754-764, 2018.

[27] E. Mohtarami, A. Baghbanan, M. Eftekhari, and H. Hashemolhosseini, "Investigating of chemical effects on rock fracturing using extended finite element method," Theoretical and Applied Fracture Mechanics, vol. 89, pp. 110-126, 2017.

[28] K.-B. Min, J. Rutqvist, C.-F. Tsang, and L. Jing, "Stress-dependent permeability of fractured rock masses: a numerical study," International Journal of Rock Mechanics and Mining Sciences, vol. 41, no. 7, pp. 1191-1210, 2004.

[29] J. Taron and D. Elsworth, "Thermal-hydrologic-mechanicalchemical processes in the evolution of engineered geothermal reservoirs," International Journal of Rock Mechanics and Mining Sciences, vol. 46, no. 5, pp. 855-864, 2009.

[30] Z. Zhao, L. Liu, I. Neretnieks, and L. Jing, "Solute transport in a single fracture with time-dependent aperture due to chemically medicated changes," International Journal of Rock Mechanics and Mining Sciences, vol. 66, pp. 69-75, 2014.

[31] W. B. Durham, W. L. Bourcier, and E. A. Burton, "Direct observation of reactive flow in a single fracture," Water Resources Research, vol. 37, no. 1, pp. 1-12, 2001.

[32] I. Yurtdas, S. Y. Xie, N. Burlion, J. F. Shao, J. Saint-Marc, and A. Garnier, "Deformation and permeability evolution of petroleum cement paste subjected to chemical degradation under temperature," Transport in Porous Media, vol. 86, no. 3, pp. 719-736, 2011.

[33] Y. Jiang, W. Y. Yang, and L. Ma, “Aperture evolution of single fracture in granite under triaxial compressive stress and chemical solution seepage," Chinese Journal of Rock Mechanics and Engineering, vol. 31, no. 9, pp. 1869-1878, 2012. 

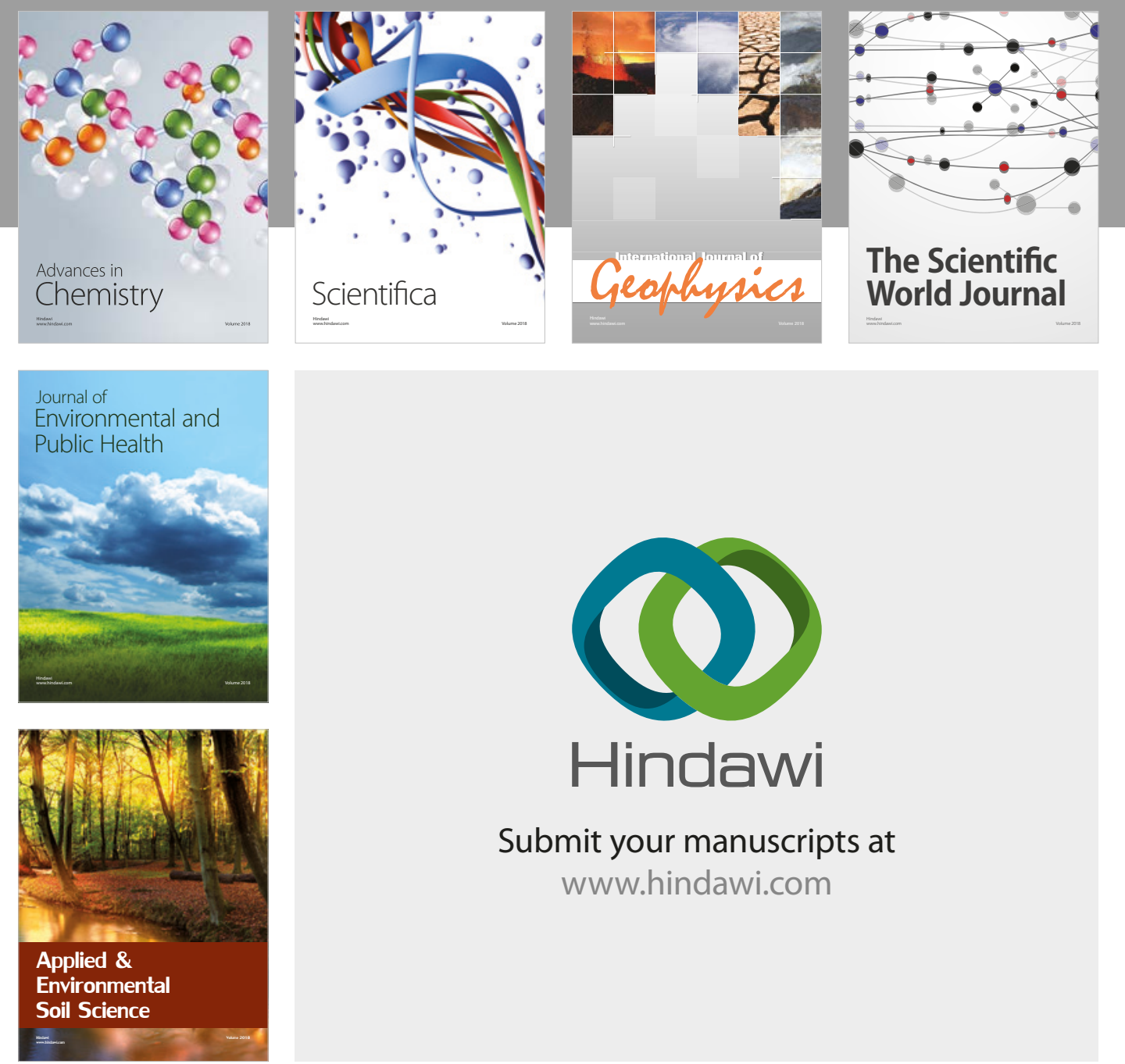

The Scientific

\section{World Journal}
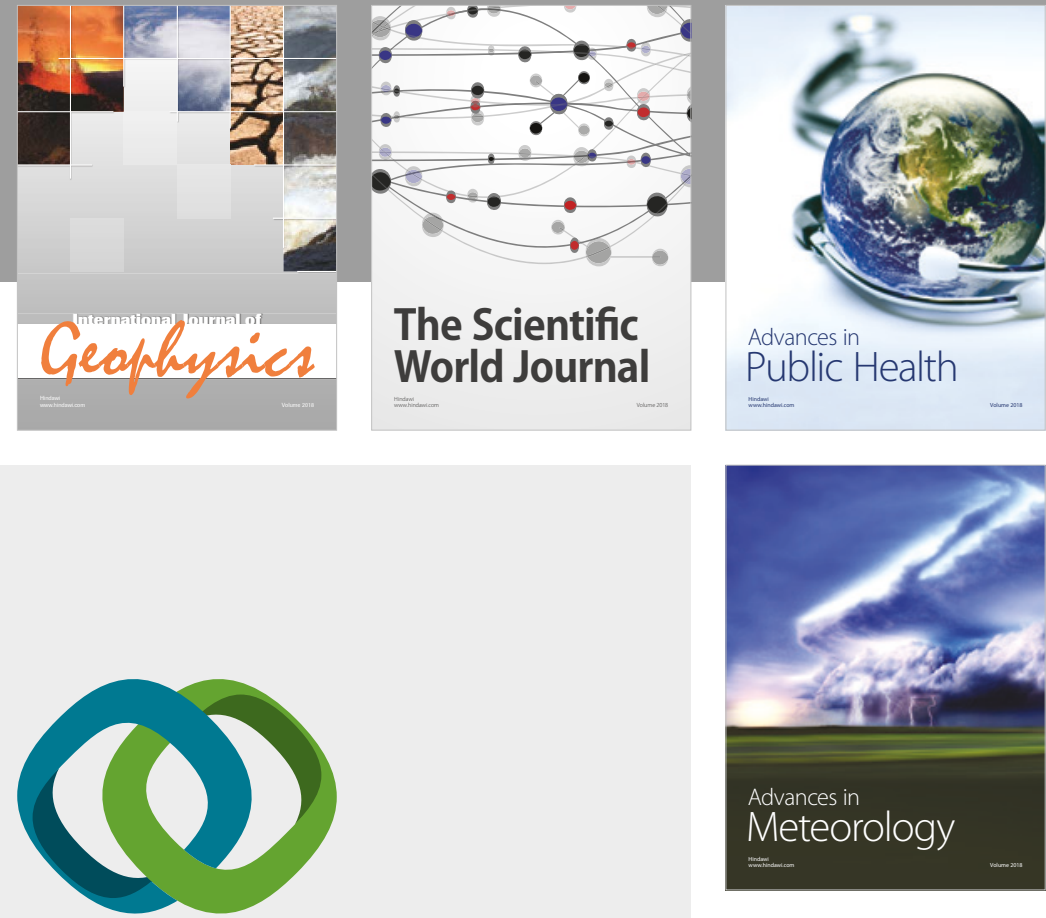

Advan

Public Health

\section{Hindawi}

Submit your manuscripts at

www.hindawi.com
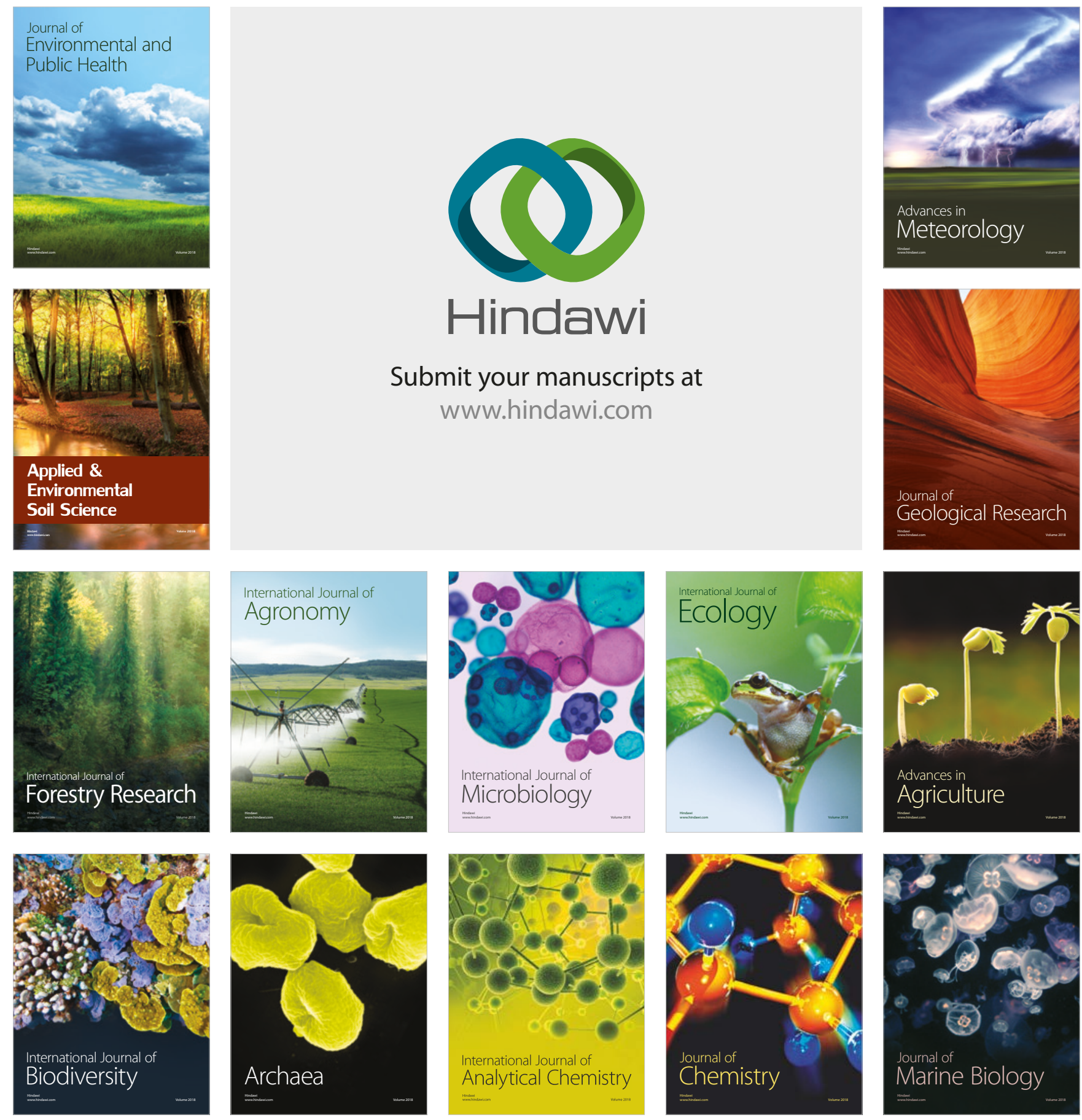